\title{
Thermodynamics aspects of a resonant method for detection and destruction of pathogens
}

\author{
Marian Trela ${ }^{1, *}$, and Roman Kwidziński ${ }^{2}$ \\ ${ }^{1}$ Gdańsk School of Higher Education, Biskupia 24B, 80-875 Gdańsk, Poland \\ ${ }^{2}$ Institute of Fluid Flow Machinery, Polish Academy of Sciences, Fiszera 14, 80-231 Gdańsk, Poland
}

\begin{abstract}
The aim of the paper is to clarify the way by which pathogens in human body may be detected and destroyed during a flow of high frequency pulsating direct current (PDC), positively polarized, under the condition of electric resonance. The method was discovered by Dr. H. Clark. However she did not clarify the physical basis of the phenomenon. The authors consider the resonant method using principles of thermodynamics and electric current laws. The phenomena of inductance and capacitance are discussed. A measure of total resistance to PDC is represented by electric impedance $(\mathrm{Z})$, which depends on the Ohm resistance $(R)$, specific inductance $(L)$, and capacitance $(C)$. The analytical formula for resonance frequency $f_{r}$ as a function of conductance $L$ and capacitance $C$ is found. At the resonance the impedance goes to minimum and therefore the current intensity increases rapidly to its maximum value. Due to JouleLenz law the heat generation is proportional to the squared electric current intensity. This is manifested by sharp increase of a pathogen temperature. The temperature increase destroys pathogens. The second destructive action for pathogen comes from polarization forces which prevent a pathogen entrance to a body cell. The third positive thermodynamic aspect, with respect to pathogen destruction, comes from oscillatory heat generation which induces the oscillatory movements, local pressure fluctuation and leads to the mechanical destruction. It is worth to know that the method discussed above is valid for specific pathogen either alive or dead. It may be also used for detection of toxin, that is, inanimate matter. This was confirmed by Dr. Clark research.
\end{abstract}

\section{Notation}

c $\quad$ - specific heat, $\mathrm{J} /(\mathrm{kgK})$,

I - electric current RMS value, $\mathrm{mA}$,

$U$ - voltage, $\mathrm{V}$,

$R \quad-$ Ohm electrical resistance, $\Omega$,

$X \quad$ - reactance, $\Omega$,

$L \quad-$ specific inductance, $\mathrm{H}$,

$C$ - capacitance, $\mathrm{F}$,

$m \quad-$ mass, $\mathrm{kg}$,

$Q \quad$ - heat energy, J,

$t \quad-$ time, s,

$f \quad-$ electrical frequency, $1 / \mathrm{s}$,

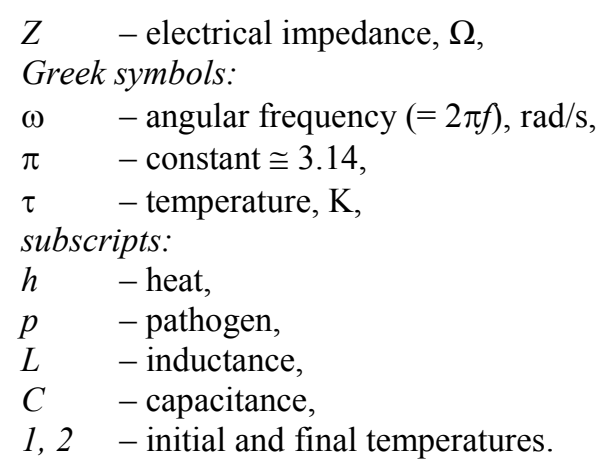

\section{Introduction}

In twentieth and twenty-first century human health is facing new challenges related to heavy pollution of the natural environment by chemicals, heavy metals etc., as well as development of various harmful pathogens. These pathogens develop rapidly in a contaminated environment.

At present antibiotics-based destruction of pathogens is less effective due to at least two reasons (1) formation of antibiotic-resistant bacteria and (2) serious side effects

caused by medications. Regarding the first reason, press information about bacteria resistant to antibiotics can be cited, e.g. [1]. The World Health Organization (WHO) has presented a list of 12 types of bacteria that antibiotics do not work on. Bacteria resistant to antibiotics are dangerous because we do not know how to stop their expansion. We do not have a way (according to official medicine) to protect against them. These 12 bacteria include, for example, bacteria: "New Delhi" or Klebsiella pneumoniae, as well as a microbe that is a

\footnotetext{
Corresponding author: marian.trela@imp.gda.pl
} 
mutation of the E. coli bacterium. According to the WHO, around 700,000 people die annually worldwide due to infection with bacteria that are drug resistant. It is estimated that if the situation does not change, in 2050 these bacteria will already kill about 10 million people a year.

As far as the side effects of antibiotics are concerned, one can cite the emergence of a disease called Candida mycosis [2]. It arises due to the excessive use of antibiotics, which also destroy beneficial bacteria in the human body. A free living space is created for the development of other "residents" in the body. The resulting void is inhabited by yeasts, which in normal conditions are harmless but then change their form and produce harmful fungi. Candida albicans is the best known yeast of this kind [2]. It is a very dangerous fungus resistant to antibiotics. It occurs mainly in the large intestine, where it grows roots that puncture the circulatory system through the walls of the intestine. Through these leaks, toxic wastes (secretions) from these fungi called mycotoxins get to the blood. These poisons flow with blood to all organs and cells of the body, causing discomfort in various parts of the body. This disease, called the plague of the 21 st century, is difficult to detect due to the lack of specialists in this field.

The present work will discuss methods for destroying pathogens in human body using electricity. There are several such methods but the most popular among them is a resonant method (earlier called bio-resonant method) developed by Dr. H. Clark [3]. This method destroys a host of pathogens including viruses, it is cheap, safe to use and has no side effects.

\section{Resonant method of Dr. H. Clark}

In 1988, Dr. H. Clark [3] made a ground-breaking discovery. She passed modified current through a test plate containing selected pathogen. This current was produced in so called acoustic generator. It used pulsating direct current (PDC), positively polarized with voltage ranging from 1 to 9 volts. At a certain frequency current amplification took place, which was indicated by acoustic signal. This amplification was due to occurrence of electrical resonance. As it was discovered later, this resonance frequency was a characteristics feature of living as well as inanimate matter. In further studies, Dr. Clark demonstrated that pathogens were destroyed after prolonged exposure to resonant frequencies. These pathogens included viruses, worms, tapeworms, trematodes and others.

In the study of Dr. Clark's resonant method, pulsating and positively polarized pulsating current was produced in two devices: in the current generator and in the zapper.

\subsection{Work with the generator}

In this case, the pulsating current generator is set to the resonant frequency of the pathogen detected previously during the diagnosis. The view of such voltage profiles from the modern current generator is shown on Fig. 1 and 2 for two different frequencies $f$. Vertical axis corresponds to voltage, horizontal to time.

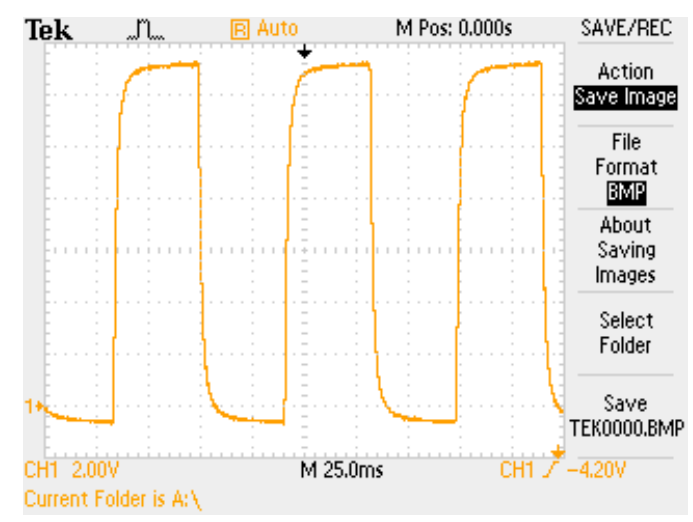

Fig. 1. Voltage $U=0.5-13.5 \mathrm{~V}$, frequency $f=100 \mathrm{kHz}$.

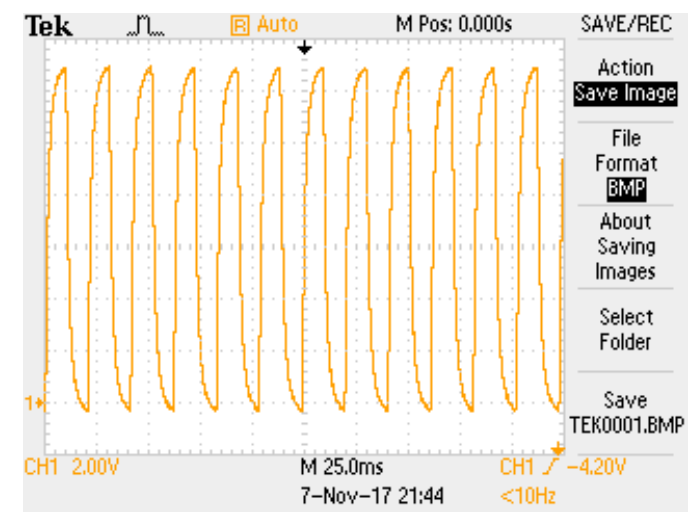

Fig. 2. Voltage $U=0.5-13.5 \mathrm{~V}$, frequency $f=400 \mathrm{kHz}$.

As can be seen, the profile of voltage $U$ of the pulsing current (PDC) is close to the rectangular wave for the lower frequency $f$ value. The above profiles were tested for the VFT3 current generator, which in Poland is intended for private use. Before the use the accuracy and shape of the signal was tested using a high-quality oscilloscope. It is worth noting that the voltages shown in Fig. 1 and Fig. 2 represent a direct (positively polarized) current flow with a time-varying amplitude, called pulsating (PDC). In this case, there is no change in the direction of current flow as it occurs for alternating current $(\mathrm{AC})$, but the voltage and current vary over time. Thus, as it is for the AC, one can also talk about the mean values of the PDC, called RMS values for current $I$ and for voltage $U$.

\subsection{Work with Zapper}

Dr. Clark also worked with the Zapper. This type of device generates a polarized pulsating electric current with a voltage profile close to square and a frequency of 4 or $30 \mathrm{kHz}$, typically. Originally it was powered by a 9 $\mathrm{V}$ battery with a supply current of about $1 \mathrm{~mA}$ and a frequency of $30 \mathrm{kHz}$. Its operation is based on the principle known in electronics (resulting from the Fourier analysis) that the square voltage waveform contains, in addition to the fundamental frequency (here 
$30 \mathrm{kHz}$ ), harmonic frequencies (components) being odd multiples of this fundamental frequency. In the range from 30 to $450 \mathrm{kHz}$, where the frequencies of most bacteria, viruses and other pathogens are located, there are the following harmonic frequencies [4]:

$$
\begin{aligned}
& 30 \mathrm{kHz} 90 \mathrm{kHz} 150 \mathrm{kHz} 210 \mathrm{kHz} \\
& 270 \mathrm{kHz} 330 \mathrm{kHz} 390 \mathrm{kHz} 450 \mathrm{kHz}
\end{aligned}
$$

There are $60 \mathrm{kHz}$ gaps between the harmonics in which Zapper does not work. This is a downside to working with Zapper, because certain pathogens are not reachable for it. An attempt was made to remedy this by adding the option of frequency adjustment within the range of 20$50 \mathrm{kHz}$. This feature has not been accepted and currently programmable pulsating current generators are being used, in which a frequency sequence is created to destroy the previously detected pathogens.

\subsection{The resonant method in use}

Dr. Clark resonant method is widely used in the world. Her detection method has been improved and is automatic now. Using Swiss made "F-scan" device, with pulsating direct current (PDC), detection takes approx. 7 minutes. Fig. 3 below shows a view of a computer screen during detection of pathogens by Dr. H. Clark method. Current plot as a function of frequency, $I=F\left(f_{r}\right)$, shows presence of 8 pathogens, for which the resonant current flow exceeds the reference value (horizontal line). Below this line are smaller peaks due to traces of other microorganisms.

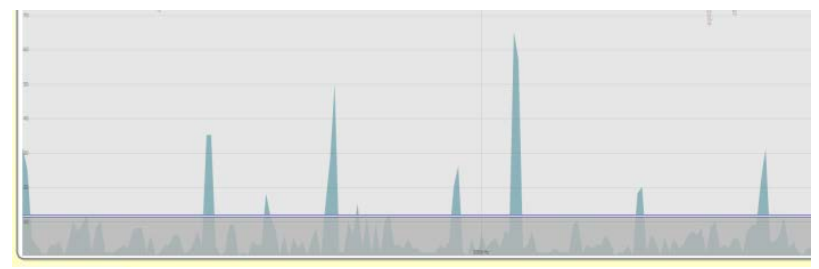

Fig. 3. View of computer screen in the Dr. Clark detection method. Vertical axis corresponds to current $I$, horizontal to pathogens resonance frequencies $f_{r}$.

Dr. Clark's resonant method for detection and destruction of parasites has no rational physical explanation. There are some explanations of this method based on quantum physics, considering electromagnetic waves. According to Dr. Clark [3] every living organism emits radiation, which she called bio-radiation. It was supposed to be a weak magnetic field at a specific frequency.

She assumed that an organism is destroyed when it is subjected to a current frequency of this field. This cannot be valid since it is difficult to determine the frequency of an unknown magnetic field. Also, Dr. Clark theory cannot explain experimentally observed facts that resonant frequencies of alive and dead pathogens are similar. This shows that the phenomenon of resonance is not related to a biological field. The same applies to the detection of toxins, that is, inanimate matter. Dr. Clark herself admitted in her book [3] that she did not understand this phenomenon and suggested further research.

Using principles of thermodynamic and laws of electrical engineering the authors are undertaking explanation of Dr. Clark's method for detection and destruction of pathogens.

\section{Alternating current flow}

It is well known that for the direct current (DC), the relation between voltage $U$, current $I$ and resistance $R$ is provided by the Ohm law, namely

$$
I=\frac{U}{R}
$$

For the alternating current (AC), the situation is more complicated. This current is usually generated in alternators (rotating machines) and has a sinusoidal waveform [5]. In this current there are two additional phenomena related to inductance and electric capacity. Under the influence of changes in the electric current through the circuit, the phenomenon of self-induction appears, manifested by the emergence of electromotive force. It is described by the following equation [5]:

$$
e=-L \frac{\Delta i}{\Delta t}
$$

where $L$ is called the coil self-inductance, $\Delta i / \Delta t$ is the rate of current change in the coil and $e$ is the induced electromotive force.

The second phenomenon is related to electric capacity $\mathrm{C}$ of the $\mathrm{AC}$ circuit. It is described by equation

$$
i=C \frac{\Delta u}{\Delta t}
$$

where $\Delta u=e$ is the induced voltage (electromotive force) and $i$ is the electric current.

Taking into account the two additional phenomena [5] for alternating current (AC) i.e. inductance and capacitance, the link between effective voltage $U$ and effective current I provides Equation (4). It is seen from this Equation that total resistance, called impedance $\mathrm{Z}$ of $\mathrm{AC}$ circuit, is larger than resistance $\mathrm{R}$ in Equation (1)

$$
I=\frac{U}{\sqrt{R^{2}+\left(\omega L-\frac{1}{\omega C}\right)^{2}}}=\frac{U}{Z},
$$

Two additional resistances appear in impedance $\mathrm{Z}$

$$
Z=\sqrt{R^{2}+\left(\omega L-\frac{1}{\omega C}\right)^{2}}
$$

Thus impedance $Z$ in Eq. (5) can be presented as a function of resistances $R, X_{L}$ and $X_{C}$, 


$$
\begin{aligned}
Z & =\sqrt{R^{2}+\left(\omega L-\frac{1}{\omega C}\right)^{2}}= \\
& =\sqrt{R^{2}+\left(X_{L}-X_{C}\right)^{2}}=\sqrt{R^{2}+X^{2}}
\end{aligned}
$$

where:

$$
\begin{aligned}
& X_{L}=\omega L-\text { inductive reactance, } \\
& X_{C}=\frac{1}{\omega C}-\text { capacitive reactance, } \\
& X=X_{L}-X_{C}-\text { resultant reactance. }
\end{aligned}
$$

Resistances $R, X_{L}$ and $X_{C}$ are related with currents and voltages. When resultant reactance in (6) equals zero:

$$
X=X_{L}-X_{C}=0,
$$

then this case is called electric resonance (of voltages). Current flow in this case is shown in Fig. 4 for classic electrical installation [5] with AC. By comparing Fig. 3 and 4 one can see large similarity between current flows in both cases. At resonance, electric current increases rapidly for both cases i.e. AC and PDC. Its maximum value depends only on $\mathrm{Ohm}$ resistance $R$. Therefore one can postulate that for $\mathrm{AC}$ and $\mathrm{PDC}$ the resonance phenomena may be described by using principles of electrical engineering.

If this resistance decreases rapidly, then the maximum current value increases strongly. This often leads to so-called overvoltage during which temperature rises and fuses blow in a domestic electric installation for $\mathrm{AC}$, as a result of an increase of heat release from flowing current, Eq.(8).

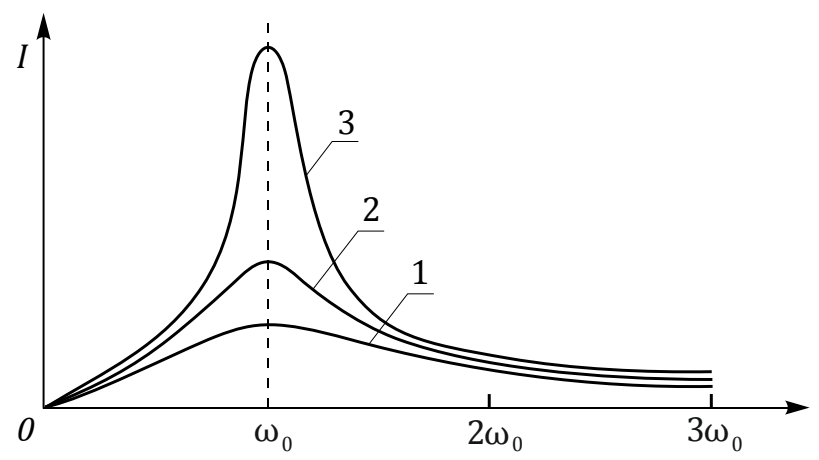

Fig. 4. Resonance characteristics $I=f(\omega)$ at different values of resistance R: $1 \mathrm{R}(1), 1 / 2 \mathrm{R}$ (2) and $1 / 5 \mathrm{R}$ (3) in domestic installation [5].

Heat produced by electric current is described by JouleLenz formula,

$$
Q_{h}=R I^{2} t
$$

Equation (7) can be expressed as

$$
\left(\omega L-\frac{1}{\omega C}\right)=0 \text {, }
$$

from which is obtained a quadratic equation

$$
\omega^{2} L C=1
$$

From Eq. (10) the value of the angular velocity $\omega$ (called also angular frequency) under resonance conditions is obtained

$$
\omega=\sqrt{\frac{1}{L C}} .
$$

Considering the relationship between the angular velocity $\omega$ and frequency $f$, one can obtain expression for $f_{r}$ in resonant conditions

$$
f_{r}=\frac{1}{2 \pi} \sqrt{\frac{1}{L C}}=0,159 \sqrt{\frac{1}{L C}} .
$$

As it is seen, the resonant frequency depends only on values of material properties $\mathrm{L}$ and $\mathrm{C}$, and thus on the type of pathogen. This finding agrees well with Dr. Clark [3] results of experimental research that for a given pathogen, dead or alive, the resonant frequency differs slightly. It should be noted here that the results of the above analysis, confirmed by Dr. Clark research is valid for the PDC.

\subsection{Skin effect}

It is known from the theory of electricity [6] that the alternating current density is largest near the conductor surface. This is called the skin effect which limits the flow of high frequency current to the outer layers of the conductor, preventing its penetration into the deeper layers. It is worth to consider this effect here due to the application of such currents in the diagnosis and destruction of human pathogens. Sometimes, erroneous opinions are also found that due to the skin effect, the resonant method cannot be effective.

The skin effect may be described by the so-called skin depth $\delta$ or magnetic diffusion depth. If this depth is very small, it means that the current flows practically on the surface of the conductor and does not penetrate into its interior. Referring this issue to human therapy, one can consider the penetration of current into, for example, the intestines in which various pathogens exist.

The skin depth $\delta$ is given by the formula

$$
\delta=\sqrt{\frac{2}{\mu \omega \sigma}},
$$

where:

$$
\begin{aligned}
& \mu-\text { magnetic permeability, } \\
& \omega-\text { angular frequency of current }(=2 \pi f), \\
& \sigma-\text { conductivity of the conductor. }
\end{aligned}
$$

It follows that if the conductivity of the medium (e.g. intestine) is small, the skin depth will be greater. In Table 1 above, skin depths for different materials have been collected [7]. 
Table. 1. Skin depth $\delta$ of common materials for selected current frequencies $f$ [7].

\begin{tabular}{|l|c|c|c|c|}
\hline$f=$ & $60 \mathrm{~Hz}$ & $1 \mathrm{kHz}$ & $1 \mathrm{MHz}$ & $1 \mathrm{GHz}$ \\
\hline copper & $8.61 \mathrm{~mm}$ & $2.1 \mathrm{~mm}$ & $0.067 \mathrm{~mm}$ & $2.11 \mu \mathrm{m}$ \\
\hline iron & $0.65 \mathrm{~mm}$ & $0.16 \mathrm{~mm}$ & $5.03 \mu \mathrm{m}$ & $0.016 \mu \mathrm{m}$ \\
\hline sea water & $32.5 \mathrm{~m}$ & $7.96 \mathrm{~m}$ & $0.25 \mathrm{~m}$ & $7.96 \mathrm{~mm}$ \\
\hline wet soil & $650 \mathrm{~m}$ & $159 \mathrm{~m}$ & $5.03 \mathrm{~m}$ & $0.16 \mathrm{~m}$ \\
\hline
\end{tabular}

Limiting the considerations to the penetration of pulsed currents into the human intestines, then the depth of penetration can be estimated as follows. Based on the data from Table 1, it can be assumed that the intestinal content will have conductivity value between sea water and wet soil. Referring to the frequency of pathogens most dangerous to human health, they have resonant frequencies in the interval of $\mathrm{f}=400 \div 450 \mathrm{kHz}$ [3]. For these frequencies, the value of $\delta$ estimated from Table 1 will be at least of the order of $1 \mathrm{~m}$. Therefore, the resonant method can be used to eliminate pathogens inside the body.

Performing the diagnosis for the presence of pathogens after the first round of therapy, it will turn out whether the pathogens have been eliminated or not. If not, then one more cycle of destroying them must be done. The practice of therapeutic cabinets shows that after two such destruction cycles, the diagnosis no longer shows the presence of these pathogens.

The second argument for the possibility of using the pulsating currents for therapy in Dr Clark's resonant method comes from the physics of the phenomenon itself. In resonance conditions, current and resistances due to inductance and electrical capacitance disappear. Only the electrical resistance described by Ohm's Law for direct current (DC) is left. As there is no skin effect for DC, then do not exist restrictions on the skin depth $\delta$.

\section{Destruction of pathogens by electric resonant method}

Considering physics of electric resonance one can expect simultaneous occurrence of three physical phenomena taking place during pathogen destruction:

- thermal destruction by increase of pathogen temperature by heat release from current during resonance - similar to pasteurization effect,

- mechanical destruction by polarized current effect and induced oscillation,

- mechanical destruction due to oscillatory heat supply causing the pressure inside the pathogen to increase and its break up into pieces.

\subsection{Temperature effect}

The amount of thermal energy $Q_{h}$ produced during current flow is described by Joule-Lenz law (8). Assuming that it is absorbed by pathogens, this heat $Q_{p}$ can be described as

$$
Q_{p}=m_{p} c\left(\tau_{2}-\tau_{1}\right) .
$$

From $Q_{h}$ and $Q_{p}$, Eq. (8) and (14), one can derive equation

$$
R I^{2} t=m_{p} c\left(\tau_{2}-\tau_{1}\right)
$$

and calculate the final pathogen temperature $\tau_{2}$

$$
\tau_{2}=\tau_{1}+\frac{R I^{2} t}{m_{p} c} .
$$

if the following parameters are known: time of the operation $t$, resistance $R$, resonance current $I$, specific heat $c$, pathogen mass $m_{p}$ and initial temperature $\tau_{1}$. It might be difficult to determine all these parameters for calculating final temperature $\tau_{2}$. But it is possible to make approximate calculations. It is seen from Eq. (16) that final temperature $\tau_{2}$ of a pathogen is proportional to the time $t$ of the operation.

Temperature effect is a very important factor in destruction of the pathogens. To illustrate this lets consider infection by influenza virus [8]. Infection takes place when virus enters a cell. Then it changes the cell DNA to replicate new viruses at a stunning rate. The entrance occurs at a site of interaction of virus protein envelope with the cell membrane. This is called a conductance channel [3]. If the input site is impaired, (pasteurization effect) the virus cannot enter the cell and cell infection will not happen. That is how the destructive effect of electric current on viruses is explained in [8]. Electric current flow produces JouleLenz heat, increasing the temperature locally. Temperature increase impairs the virus protein shell, preventing it from entering the cell. Such virus remains outside the cell to be destroyed by an immune system.

Fighting the influenza virus by increasing body temperature is described in [9]. French professor Andre Lwoff (Nobel prize winner in medicine in 1965) demonstrated that even a tiny temperature increase by $0.5^{\circ} \mathrm{C}$ caused dramatic decrease of polio virus reproduction speed. Therefore a good protection against influenza virus would be increasing body temperature by drinking hot liquids, taking hot bath, sweating in bed, etc. Similar destructive effect of temperature on other pathogens also exists by impairing their proteins.

\subsection{Polarization effect}

Dr. Clark and other researchers reported that sinusoidal current with positive voltage in a first half of a period and negative in second half, was not useful for pathogens destruction [3]. In Dr. Clark's method, voltage was positively polarized. At this condition current polarization occurs, followed by force effect of current on pathogens. Figure 5 illustrates polarization effect for a dielectric [10]. In case (a) atom is electrically neutral since distribution of positive and negative charges is symmetric. In case (b) external electric field induces shift of charges and the atom system becomes asymmetric. This case might simulate Dr. Clark method. 
a)



b)

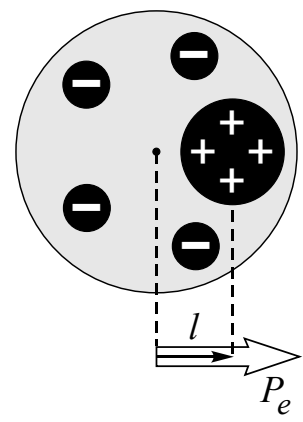

Fig. 5. Polarization of a dielectric [10]: (a) symmetric distribution of electric charges in atom (minuses represent electrons, pluses protons), (b) asymmetric charge distribution due to atom polarization by external electric field $\left(P_{e}-\right.$ dipole moment).

Positively polarized current attracts negative charges causing separation of charges in pathogens. Since negative charges are removed from the vicinity of conductance channel, pathogens are not able to penetrate the cells [3]. In addition oscillating current induces oscillating movements of pathogens leading to mechanical destruction due to large inertia forces.

\subsection{Effect of oscillatory heat supply}

This effect is very important. It may be clarified using Thermodynamics principles. Treating a pathogen as a thermodynamics system one can apply the well-known Van der Waals equation of state

$$
\left(p+\frac{a}{v^{2}}\right)(v-b)=R T
$$

where $a, b$ are individual constants and $v$ is specific volume, $v=V / m$.

For the purpose of the analysis, Eq. (17) can be written as

$$
p_{p} v_{p}=R T_{p}
$$

or

$$
p_{p} \frac{V_{p}}{m_{p}}=R T_{p} .
$$

Assuming that the volume $V_{p}$ and the mass $m_{p}$ of the pathogen are constant, then one gets the following important equality

$$
\frac{p_{p}}{T_{p}}=\frac{m_{p} R}{V_{p}}=\text { const } .
$$

It follows from Eq. (20) that supplying heat to the pathogen increases its temperature and pressure. At certain time the pressure reaches very high value which causes the pathogen to break up into pieces.

These theoretical considerations have been confirmed experimentally. In [13], an experiment was described in which the pathogen Gardia lamblia was exposed to

resonant current. Its behaviour was observed using a microscope. In the initial phase this pathogen rotated but at some later time it rapidly disintegrated into shreds.

\subsection{Pathogen resonant frequencies}

Dr. Clark has experimentally determined resonant frequencies for around 270 pathogens. The tables 2 and 3 show some of them.

Table 2. Selected frequencies for bacteria and viruses [3].

\begin{tabular}{|l|l|}
\hline \multicolumn{1}{|c|}{ Pathogen } & Frequency [kHz] \\
\hline Adenowirus & 393 \\
\hline Borellia burgdorferi & 380 \\
\hline Campylobacter pyloridis & 355 \\
\hline Candida Albicans & 386 \\
\hline Chlamydia pneumoniae & 382.5 \\
\hline Coxsackie wirus B1 i B4 & $364,362.5$ \\
\hline Diplococcus pneumoniae & 365,360 \\
\hline Epsteina - Barr Virus & 380,375 \\
\hline Enterobacter aerogenes & 374 \\
\hline Escherichia coli (E.coli) & 356,393 \\
\hline Gardnerella vaginalis & 340 \\
\hline Hameophilus influenzae & 336 \\
\hline Hepatitis B antigen & 418 \\
\hline Histoplasma capsulatum & 302 \\
\hline Herpes simplex & $292,345.5$ \\
\hline Herpes Zoster & 418 \\
\hline HIV & 365 \\
\hline Klebsiella pneumoniae & 401,419 \\
\hline Mykoplazma & $323.5,346$ \\
\hline Mycobacterium tuberculosis & 432 \\
\hline Neisseria gonorrhea & 334 \\
\hline Proteus vulgaris & $413,336,328$ \\
\hline Salmonella enteriditis & 329 \\
\hline Staphylococcus aureus & 385.85 \\
\hline Streptococus pneumoniae & 368 \\
\hline Respiratory syncyt. virus & 380 \\
\hline
\end{tabular}

\section{The health factors}

Everyone is interested in health and having long and healthy life. It is worth to know what are the factors affecting our health. The World Health Organization (WHO) presented document on this subject at WHO conference in Ottawa in 1986. This document was later published. Text of this document was available in 2011 on website of the Mazovian Health Fund (Mazowiecki Fundusz Zdrowia). Professor of medicine Barbara Woynarowska from Warsaw University included basic thesis of this document in her lecture in 2014 [11]. Using 1974 report by M. Lalonde (former Canada Minister of 
Public Health and Welfare), WHO adopted in 1986 factors determining human health and described their relative contributions. These are: lifestyle contributing $50 \%$, environment $20 \%$, genetics $20 \%$, and healthcare $10 \%$.

Table 3. Selected frequencies for roundworms, flatworms, onecelled animals [3].

\begin{tabular}{|l|l|}
\hline \multicolumn{1}{|c|}{ Pathogen } & Frequency $[\mathrm{kHz}]$ \\
\hline Ascaris & 408 \\
\hline Capilaria hepatica & 428 \\
\hline Clonarchis sinensis & 427 \\
\hline Dirofilaria immitis & 409 \\
\hline Enterobius vermicularis & 423 \\
\hline Eurytrema pancreaticum & 421 \\
\hline Fasciola hepatica & 425 \\
\hline Fasciola buski & 434 \\
\hline Trichomonas vaginalis & 381 \\
\hline Trichuris sp. & 406 \\
\hline Gardia lamblia & 424 \\
\hline Paragonimus Westermanii & 452,447 \\
\hline Strongyloides & 400 \\
\hline Trichinella spiralis & 404.5 \\
\hline Loa Loa & 361 \\
\hline Ancylostoma caninum & $400,393,386$ \\
\hline
\end{tabular}

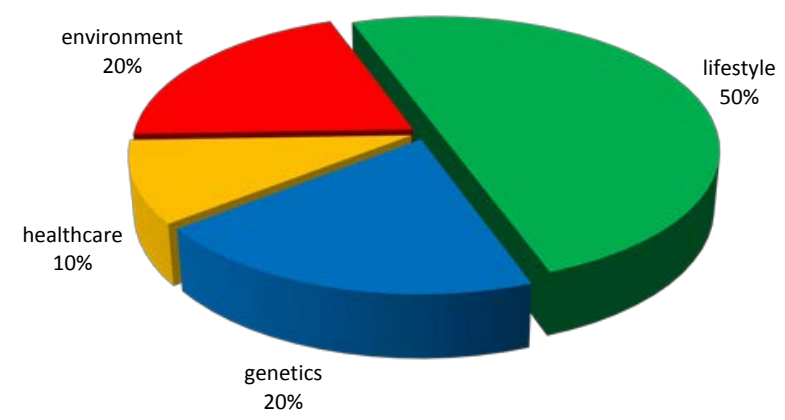

Fig. 6. Health factors according to Lalonde and WHO [11].

From Fig. 6 one can see that contribution of academic medicine on our health is very small $(10 \%)$ comparing to that of a lifestyle (50\%). Such a low impact of academic medicine on human health results from excessive use of chemical drugs and inevitable medical errors.

Danish physician and medical researcher Prof. Peter C. Gøtzsche in his last book [12] reports that drugs are the third cause of death in US and Europe after heart disease and cancer.

It is clear that we are, to a large extend, responsible for our health. It would be worthy to consider simple, natural treatments that anyone can do on their own, or specialized methods such as the destruction of pathogens discussed in this work.

\section{Concluding remarks}

The aim of this work is to provide mathematical description of Dr. Clark resonant method used for detection and destruction of pathogens in human body, based on the laws of electric current flow and thermodynamics. Basic laws governing the flow of alternating and pulsating direct current (PDC) are presented as well as phenomena of resonance, inductance and capacitance.

Analytical formula describing resonant frequencies as a function of two material parameters of pathogen is obtained. It is also shown that skin effect does not occur during the resonance.

The mechanisms of pathogen destruction by electric current are outlined. The main factors of pathogens destruction are: local increase of their temperature (causing damage of pathogen protein structures), polarization forces (inducing their oscillatory movements) and effects of heat supply (increasing a pressure inside pathogen), which cause the pathogen to break up into pieces. The first factor, related to temperature increase, is similar to pasteurization process. It is worth to know that the method discussed above is valid for specific pathogen either alive or dead. It may be also used for detection of toxins, that is inanimate matter.

\section{Formal matters}

According to law, medical treatment can be carried out only by a physician. Therefore, the following statement should be made:

All information's regarding the therapeutic method of destroying pathogens is given here only for cognitive purposes. Before use, please consult your doctor. The authors do not take any responsibility for the consequences if someone would like to check them on their own.

Acknowledgement: The authors would like to thank Dr. Krystyna Wyrzykowska from Columbus, Ohio USA, for her contribution.

\section{References}

1. T. Rożek, Will bacteria kill us? (in Polish), Gość Niedzielny, No 13 (2017).

2. A. Janus, Do not be eaten by Candida fungi (in Polish), Wydawnictwo IPS, Warsaw, 2011.

3. H.R. Clark, The Cure For All Diseases, New Century Press, Chila Vista CA, USA ,1995.

4. J. Żurek, Cure of life (in Polish), Optymalnik, March 2004.

5. R. Kurdziel, Fundamentals of electrical engineering, Part 1 (in Polish), Wydawnictwo Szkolne i Pedagogiczne, Warsaw, 1975.

6. R.P. Feynman, R.B. Leighton, M. Sands, The Feynman Lectures on Physics, Vol. II: Mainly Electromagnetism and Matter, Basic Books, New York, USA, 2011. 
7. Popovic \& B. Popovic, Introductory Electromagnetics. Chapter 20: The Skin Effect, Prentice-Hall, USA, 1999.

8. Electronic pathogen removal (in Polish), http://www.vibronika.eu/elektroniczne-usuwaniepatogenow

9. J-M. Dupuis, Detailed information about anti-viral activity (in Polish), Poczta Zdrowia, https://www.pocztazdrowia.pl/artykuly/pozwolgoraczce-rosnac
10. B.M. Jaworski \& A.A. Piński, Elements of physics, Vol. I (in Polish), PWN, Warsaw 1979, page 314.

11. B. Woynarowska, lecture "Health, its conditioning factors and the main health problems" (in Polish), Warsaw University, www.pedagog.uw.edu.pl/ materialy/wyklad_zdrowie.doc.

12. P.C. Gøtzsche, Deadly Medicines and Organised Crime. How big pharma has corrupted healthcare, CRC Press, USA, 2013.

13. M. Rojek, Slayer of intelligent bacteria (in Polish), Nieznany Świat, No 8/2016. 